\title{
Value of surgery for infective endocarditis in dialysis patients
}

\author{
Sajjad Raza, MD, ${ }^{\mathrm{a}}$ Syed T. Hussain, MD, ${ }^{\mathrm{a}}$ Jeevanantham Rajeswaran, PhD, ${ }^{\mathrm{b}}$ Asif Ansari, MD, \\ Matteo Trezzi, MD, ${ }^{\mathrm{a}}$ Amr Arafat, MD, ${ }^{\mathrm{a}}$ James Witten, BS, ${ }^{\mathrm{d}}$ Kirthi Ravichandren, MD, ${ }^{\mathrm{a}}$ Haris Riaz, MD, \\ Hoda Javadikasgari, MD, ${ }^{a}$ Sunil Panwar, MD, ${ }^{a}$ Sevag Demirjian, MD ${ }^{\mathrm{c}}$ Nabin K. Shrestha, MD, \\ Thomas G. Fraser, MD, ${ }^{f}$ José L. Navia, MD, ${ }^{a}$ Bruce W. Lytle, MD, ${ }^{a}$ Eugene H. Blackstone, MD, ${ }^{\mathrm{a}, \mathrm{b}}$ and \\ Gösta B. Pettersson, MD, $\mathrm{PhD}^{\mathrm{a}}$
}

\begin{abstract}
Objectives: To determine the value of surgery for infective endocarditis (IE) in patients on hemodialysis by comparing the nature and invasiveness of endocarditis in hemodialysis and nonhemodialysis patients and their hospital and long-term outcomes, and identifying risk factors for time-related mortality after surgery.

Methods: From January 1997 to January 2013, 144 patients on chronic hemodialysis and 1233 nonhemodialysis patients underwent valve surgery for IE at our institution. Propensity matching identified 99 well-matched hemodialysis and nonhemodialysis patient pairs for comparison of outcomes.
\end{abstract}

Results: Staphylococcus aureus infection was more common in hemodialysis patients than in nonhemodialysis patients $(42 \%$ vs $21 \% ; P<.0001)$, but invasive disease was similar in the 2 groups $(47 \% ; P=.3)$. Hospital mortality was $13 \%$ and 5-year survival was $20 \%$ for hemodialysis patients, $20 \%$ below that expected in a general hemodialysis population but $15 \%$ above that of hemodialysis patients treated nonsurgically for IE. For matched patients, hospital mortality was $13 \%$ for hemodialysis patients versus $5.1 \%$ for nonhemodialysis patients $(P=.05)$, and survival at 1 and 5 years was $56 \%$ versus $83 \%$ and $24 \%$ versus $59 \%$, respectively $(P<.004)$. Use of an arteriovenous graft for dialysis access $(P=.01)$ and preoperative placement of a pacemaker $(P<.0001)$ were risk factors for late mortality in hemodialysis patients. For matched patients, freedom from reoperation was similar in the hemodialysis and nonhemodialysis groups $(P>.9)$.

Conclusions: Intermediate-term survival after surgery for IE in hemodialysis patients is substantially worse than that in nonhemodialysis patients, but only slightly worse than that in the general hemodialysis population and substantially better than that in hemodialysis patients with IE treated nonsurgically, supporting continued surgical intervention for IE. (J Thorac Cardiovasc Surg 2017;154:61-70)

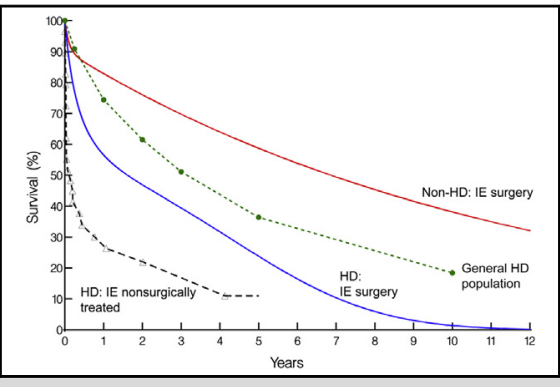

Survival of patients with infective endocarditis (IE) on or not on hemodialysis $(H D)$.

\section{Central Message}

With a 5-year survival of $24 \%$, surgery for infective endocarditis should be considered for patients on hemodialysis.

\section{Perspective}

Survival after surgery for infective endocarditis (IE) in patients receiving hemodialysis is substantially worse than for otherwise similar patients not receiving hemodialysis, but only somewhat worse than that for the general hemodialysis population and substantially better than that for hemodialysis patients with nonsurgically treated IE, supporting surgical intervention for IE in this high-risk population.

See Editorial Commentary page 71
Vascular access exposes patients on hemodialysis to a persistent source of environmental pathogens at the entry site. Consequently, the incidence of infective endocarditis

\footnotetext{
From the ${ }^{\mathrm{a}}$ Department of Thoracic and Cardiovascular Surgery, Heart and Vascular Institute, ${ }^{b}$ Department of Quantitative Health Sciences, Lerner Research Institute, ${ }^{\mathrm{c}}$ Department of Nephrology and Hypertension, Glickman Urological and Kidney Institute, ${ }^{\mathrm{d}}$ Cleveland Clinic Lerner College of Medicine, ${ }^{\mathrm{e}}$ Department of Internal Medicine, and ${ }^{\mathrm{f}}$ Department of Infectious Disease, Medicine Institute, Cleveland Clinic, Cleveland, Ohio

This study was supported in part by the Gus P. Karos Registry Fund; the Kenneth Gee and Paula Shaw, PhD, Chair in Heart Research, held by Dr Blackstone; the Peter and Elizabeth C. Tower and Family Endowed Chair in Cardiothoracic Research, held by Dr Pettersson; and James and Sharon Kennedy, the Slosburg Family Charitable Trust, Stephen and Saundra Spencer, and Martin Nielsen. Dr Raza is a Clinical Research Scholar as part of the Cardiothoracic Surgical Trials Network
}

(IE) is 18 times higher in hemodialysis patients than in the general US population. ${ }^{1}$ With more than 400,000 patients on hemodialysis in the US, the morbidity and

(CTSN), and his Master of Science in Management (MSM)-Healthcare is being funded by National Heart, Lung and Blood Institute Grant UM1HL088955.

Read at the 96th Annual Meeting of The American Association for Thoracic Surgery, Baltimore, Maryland, May 14-18, 2016.

Received for publication May 13, 2016; revisions received Jan 16, 2017; accepted for publication Feb 13, 2017.

Address for reprints: Gösta B. Pettersson, MD, PhD, Department of Thoracic and Cardiovascular Surgery, Cleveland Clinic, 9500 Euclid Ave, Desk J4-1, Cleveland, OH 44195 (E-mail: petterg@ccf.org).

$0022-5223 / \$ 36.00$

Copyright (C) 2017 Published by Elsevier Inc. on behalf of The American Association for Thoracic Surgery

http://dx.doi.org/10.1016/j.jtcvs.2017.02.063 


\section{Abbreviations and Acronyms}

IE = infective endocarditis

$\mathrm{PVE}=$ prosthetic valve endocarditis

Scanning this QR code will take you to a supplemental video, appendix, figures, and tables. To view the AATS 2016 Webcast, see the URL next to the video thumbnail.

mortality associated with IE in these patients is an important healthcare issue. ${ }^{2}$ In reports published a decade ago, operative mortality after surgery for IE in these patients ranged from $24 \%$ to $73 \%,{ }^{3-5}$ and survival was recently reported to be as low as $25 \%$ at 3 years and $0 \%$ at 5 years. ${ }^{6,7}$ To evaluate the value of surgery for IE in patients on hemodialysis, we compared the nature and invasiveness of IE and the hospital and long-term outcomes in hemodialysis and nonhemodialysis patients, contrasted their survival with that of hemodialysis patients with IE not treated surgically, and identified risk factors for time-related mortality after surgery for IE.

\section{PATIENTS AND METHODS \\ Patients}

From January 1997 to January 2013, 1413 patients underwent valve surgery for active IE at Cleveland Clinic. Of these, $144(10 \%)$ were on chronic hemodialysis (more operated on in recent years; Figure 1$), 8(0.6 \%)$ were on chronic peritoneal dialysis (Appendix E1), and 28 (2\%) were on dialysis for acute renal failure; $1233(87 \%)$ were not on any form of dialysis (nonhemodialysis patients). The 28 patients on dialysis for acute renal failure are not considered in this report.

\section{Study Design}

Surgically treated chronic hemodialysis patients and nonhemodialysis patients are the 2 primary comparison groups in this study. In addition, for survival, 3 reference groups are considered: 29 hemodialysis patients with IE not treated surgically, diagnosed between July 2007 and January 2015; age-, race-, and sex-matched individuals in the general population ${ }^{8}$; and hemodialysis patients in general (US Renal Data System, 2015 Annual Data Report Reference Tables; Reference Table I: Patient Survival). ${ }^{9}$

\section{Data}

All data used in this study were approved for use in research by the Cleveland Clinic's Institutional Review Board, with the requirement for patient consent waived. Preoperative, operative, and postoperative variables were retrieved from the prospectively maintained Cardiovascular Information Registry. Dialysis-related variables were collected through chart review, and infecting agents were adjudicated by infectious disease experts. Invasiveness data were available only for patients with IE who underwent surgery from 2002 onward (119 of 144 hemodialysis patients and 873 of 1233 nonhemodialysis patients), as described previously. ${ }^{8,10}$

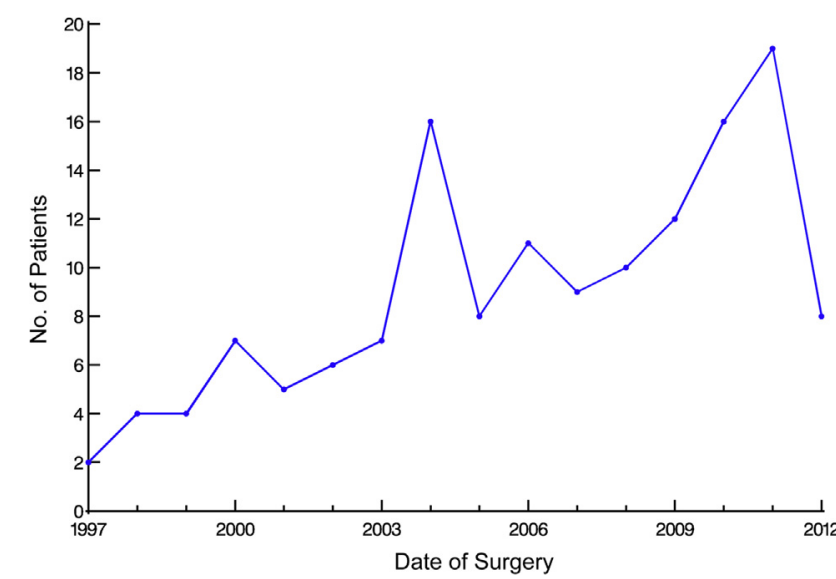

FIGURE 1. Hemodialysis patients undergoing surgery for active IE by year.

\section{Surgery for IE}

Surgical principles followed for patients with IE at Cleveland Clinic have been reported previously. ${ }^{10,11}$ A dedicated multispecialty team treats all patients presenting with IE. Preoperatively, all patients undergo brain imaging and many undergo imaging of the chest and abdomen to identify embolic complications. Surgery is advocated as soon as an indication is established, and the operation is expedited to avoid additional embolization and clinical deterioration. At surgery, radical debridement of all infected tissues and foreign material is followed by generous irrigation. Local antiseptics and antibiotics are used sparingly (Video 1).

The choice of replacement valve is based on pathology, overall complexity of the medical situation, life expectancy, and ability to comply with anticoagulation. Most hemodialysis patients received a tissue prosthesis to avoid anticoagulation (Table E1). In patients with aortic valve IE with annulus destruction and invasive disease, an allograft remains our preferred choice for aortic root reconstruction, which was used in $47 \%$ (38 of 81 ) of the hemodialysis patients undergoing aortic valve replacement. Severe mitral annular calcification is not uncommon in hemodialysis

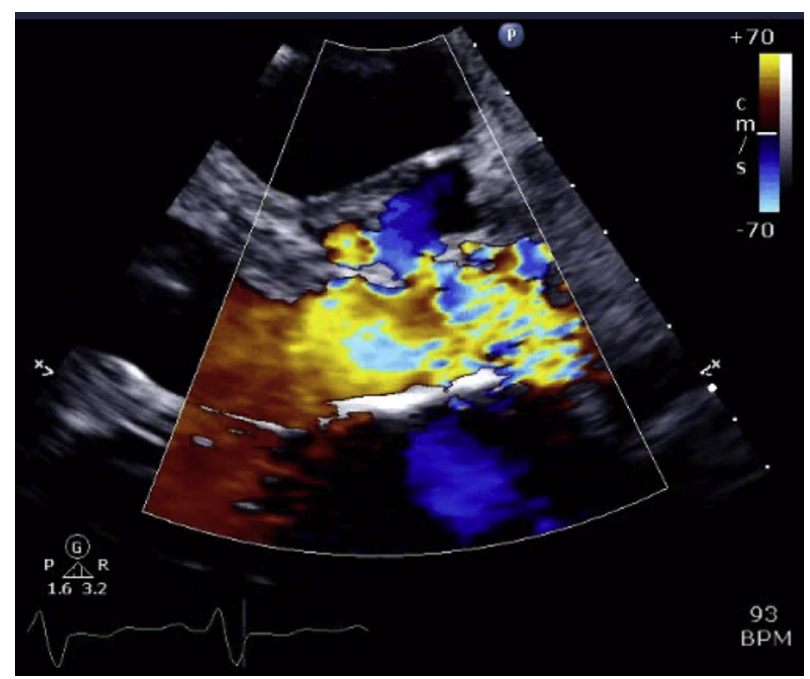

VIDEO 1. Complete debridement and allograft root reconstruction in an extreme case of aortic root infective endocarditis. Video available at: http://www.jtcvsonline.org/article/S0022-5223(17)30553-6/addons. 
TABLE 1. Patient characteristics before and after propensity matching

\begin{tabular}{|c|c|c|c|c|c|c|c|c|c|c|}
\hline \multirow[b]{2}{*}{ Characteristic } & \multicolumn{2}{|r|}{$\begin{array}{l}\text { Hemodialysis } \\
(\mathrm{n}=144)\end{array}$} & \multicolumn{2}{|c|}{$\begin{array}{l}\text { Nonhemodialysis } \\
\quad(\mathbf{n}=\mathbf{1 2 3 3})\end{array}$} & \multirow[b]{2}{*}{$P$ value } & \multirow{2}{*}{$\begin{array}{l}\text { hen } \\
\text { n* }\end{array}$} & \multirow{2}{*}{$\begin{array}{l}\text { Matched } \\
\text { ialysis }(n=99) \\
\text { No. }(\%) \text { or } \\
\text { 15th/50th/85th } \\
\text { percentiles } \\
\end{array}$} & \multirow{2}{*}{\multicolumn{2}{|c|}{$\begin{array}{c}\text { Matched } \\
\text { nonhemodialysis } \\
(\mathbf{n}=99) \\
\text { No. }(\%) \text { or } \\
\text { 15th/50th/85th } \\
\text { percentiles } \\
\end{array}$}} & \multirow[b]{2}{*}{$P$ value } \\
\hline & n* & $\begin{array}{c}\text { No. }(\%) \text { or } \\
\text { 15th/50th/85th } \\
\text { percentiles }\end{array}$ & n* & $\begin{array}{c}\text { No. }(\%) \text { or } \\
\text { 15th/50th/85th } \\
\text { percentiles }\end{array}$ & & & & & & \\
\hline \multicolumn{11}{|l|}{ Demographics } \\
\hline Age, $y$ & 144 & $40 / 55 / 66$ & 1233 & $40 / 58 / 73$ & .03 & 99 & $44 / 58 / 68$ & 99 & $42 / 62 / 73$ & .19 \\
\hline Body mass index $\mathrm{kg} \cdot \mathrm{m}^{-2}$ & 139 & $20 / 26 / 36$ & 1200 & $22 / 27 / 34$ & .8 & 95 & $21 / 28 / 37$ & 99 & $21 / 27 / 36$ & .8 \\
\hline Female & 144 & $53(37)$ & 1233 & $353(29)$ & .04 & 99 & $36(36)$ & 99 & $39(39)$ & .7 \\
\hline Black race & 143 & $44(31)$ & 1214 & $100(8.2)$ & $<.0001$ & 98 & $22(22)$ & 99 & $23(23)$ & .9 \\
\hline \multicolumn{11}{|l|}{ Cardiac comorbidity } \\
\hline Previous cardiac surgery & 144 & $45(31)$ & 1229 & $562(46)$ & .0009 & 99 & $37(37)$ & 99 & $40(40)$ & .7 \\
\hline $\begin{array}{l}\text { Left ventricular mass index, } \\
\mathrm{g} \cdot \mathrm{m}^{-2}\end{array}$ & 93 & $104 / 141 / 189$ & 796 & $86 / 123 / 172$ & $<.0001$ & 65 & $100 / 135 / 189$ & 72 & 98/132/199 & .8 \\
\hline Pacemaker & 144 & $12(8.3)$ & $-\dagger$ & 一† & - & 99 & $9(9.0)$ & $-\dagger$ & $-\dagger$ & - \\
\hline \multicolumn{11}{|l|}{ Noncardiac comorbidity } \\
\hline Dialysis access & 139 & & & & & 95 & & & & \\
\hline Arteriovenous fistula & & $69(50)$ & $-\ddagger$ & - & - & & $51(54)$ & 一 & $-\ddagger$ & - \\
\hline Arteriovenous graft & & $12(8.6)$ & $-\ddagger$ & - & - & & $4(4.2)$ & 一 & $-\ddagger$ & - \\
\hline Venous catheter & & $58(42)$ & & & & & $40(42)$ & & & \\
\hline Nonaccess source of IE & 144 & $15(10)$ & $-\ddagger$ & $-\ddagger$ & - & 99 & $10(10)$ & 一 & $一 \ddagger$ & - \\
\hline Carotid disease & 144 & $40(28)$ & 1233 & $261(21)$ & .07 & 99 & $29(29)$ & 99 & $29(29)$ & $>.9$ \\
\hline Stroke & 144 & $59(41)$ & 1233 & $349(28)$ & .002 & 99 & $40(40)$ & 99 & $40(40)$ & $>.9$ \\
\hline Peripheral arterial disease & 144 & $34(24)$ & 1233 & $114(9.2)$ & $<.0001$ & 99 & $24(24)$ & 99 & $24(24)$ & $>.9$ \\
\hline Hypertension & 144 & $140(97)$ & 1233 & $749(61)$ & $<.0001$ & 99 & $95(96)$ & 99 & 99 (100) & .04 \\
\hline $\begin{array}{l}\text { Pharmacologically treated } \\
\text { diabetes }\end{array}$ & 142 & $61(43)$ & 1213 & 235 (19) & $<.0001$ & 98 & $43(44)$ & 97 & $48(49)$ & .4 \\
\hline Active intravenous drug use & 144 & $5(3.5)$ & $-\dagger$ & $-\dagger$ & $-\dagger$ & 99 & $1(1.0)$ & 99 & $4(4.0)$ & .4 \\
\hline Bilirubin, $\mathrm{mg} \cdot \mathrm{dL}^{-1}$ & 143 & $0.30 / 0.50 / 0.90$ & 1204 & $0.30 / 0.60 / 1.3$ & .005 & 99 & $0.30 / 0.60 / 1.1$ & 95 & $0.30 / 0.50 / 1.1$ & 6 \\
\hline $\mathrm{GFR}, \mathrm{mL} \cdot \mathrm{min}^{-1} \cdot 1.73 \mathrm{~m}^{-2} \S$ & 144 & $6.6 / 11 / 18$ & 1231 & $34 / 71 / 105$ & $<.0001$ & 99 & $6.8 / 12 / 19$ & 98 & $26 / 59 / 102$ & $<.0001$ \\
\hline Cholesterol, $\mathrm{mg} \cdot \mathrm{dL}^{-1}$ & 90 & $81 / 111 / 168$ & 683 & 97/139/194 & $<.0001$ & 62 & $81 / 115 / 175$ & 59 & $94 / 121 / 177$ & .3 \\
\hline Hematocrit, \% & 140 & $24 / 28 / 33$ & 1199 & $26 / 31 / 37$ & $<.0001$ & 97 & $26 / 29 / 34$ & 98 & $25 / 29 / 33$ & .8 \\
\hline
\end{tabular}

$I E$, Infective endocarditis; GFR, glomerular filtration rate. *Patients with data available. †Data not available. $\ddagger$ Not applicable for nonhemodialysis patients. $\S$ Not included in propensity score because it defined the groups.

patients and is treated by limited calcium debridement and reconstruction as necessary to allow for an acceptable-sized valve. Whenever additional material is required for reconstruction, we prefer autologous pericardium.

\section{Endpoints}

Endpoints were in-hospital outcomes, with morbidities as defined in the Society of Thoracic Surgeons national database (available at http://www. sts.org/sites/default/files/documents/word/STSAdultCVDataSpecifications V2_73\%20with $\% 20$ correction.pdf), time-related mortality, and timerelated heart valve reoperation.

Systematic active follow-up was performed at 2 and 5 years and every 5 years thereafter, supplemented by a cross-sectional follow-up with a closing date of April 15, 2016. To verify vital status, this systematic follow-up was supplemented with Social Security Death Master File data (accessed on October 27, 2011, with a closing date of April 27, 2011) and Ohio Death Registry data.

For hemodialysis patients, median follow-up for mortality was 1.4 years, with $25 \%$ of survivors followed for $>5.6$ years and $10 \%$ followed for $>7.2$ years; 355 patient-years of data were available for analysis. For matched nonhemodialysis patients, median follow-up for mortality was 4.3 years, with $25 \%$ of survivors followed for $>8$ years and $10 \%$ followed for $>8.8$ years; 448 patient-years of data were available for analysis. At
5 years, 12 of the 198 matched patients had been lost to follow-up for vital status, including 4 within 1 year and 8 within 3 to 5 years.

Median active follow-up for reoperation in the hemodialysis patients was 5.3 months, with $25 \%$ of survivors followed for $>5.0$ years and $10 \%$ followed for $>5.5$ years; 245 patient-years of data were available for analysis. For the matched nonhemodialysis patients, median active follow-up for reoperation was 2 years, with $25 \%$ of survivors followed for $>6.0$ years and $10 \%$ followed for $>7$ years; 279 patient-years of data were available for analysis. Among matched patients alive at 5 years, follow-up for reoperation was unavailable for 22; 14 were lost to follow-up within 1 year, 2 between 1 and 3 years, and 6 between 3 and 5 years.

\section{Statistical Analysis}

All analyses were performed using SAS version 9.1 (SAS Institute, Cary, NC).

Time-related mortality and reoperation. Time-related survival and freedom from reoperation were assessed nonparametrically using the Kaplan-Meier method ${ }^{12}$ and parametrically using the multiphase nonproportional hazards model ${ }^{13}$ (for additional details, see http://www.lerner. ccf.org/qhs/software/hazard/). Because death is a competing risk for reoperation, the likelihood of reoperation was also estimated using competingrisks methodology. ${ }^{14}$ 
Risk factors for death after surgery for IE in hemodialysis patients. Multivariable analysis was performed in the multiphase hazard function domain. Using preoperative variables (Appendix E2), variable selection was performed using bagging. ${ }^{15,16}$ For this, 1000 bootstrap datasets were generated, and automated stepwise variable selection was performed to identify variables with $P \leq .05$. Results were aggregated, and variables appearing in $50 \%$ or more of the analyses were considered reliable risk factors.

Comparison with nonhemodialysis patient outcomes. Because patient characteristics differed between the hemodialysis and nonhemodialysis groups (Table 1), in the spirit of a "natural experiment" we attempted to fairly compare outcomes using propensity matching. ${ }^{14-16}$ Using multivariable logistic regression and bagging as described above, a parsimonious model of hemodialysis versus nonhemodialysis patients was developed based on the variables listed in Appendix E2, but without considering renal function (Table E2). Then other variables representing groups of patient and procedure factors that might be related to unrecorded confounding factors were added (semisaturated model with 58 variables). A propensity score was calculated for each patient by solving the resulting propensity model. Using only the propensity score, hemodialysis patients were matched $1: 1$ to nonhemodialysis patients using a greedy-matching strategy ${ }^{17}$ that yielded 99 well-matched patient pairs $(69 \%$ of possible matches; Figure E1). Hemodialysis patients whose propensity scores deviated by $>0.25$ from those of nonhemodialysis patients were considered unmatched. The 45 unmatched hemodialysis patients were younger than the 99 matched hemodialysis patients (mean age, $50 \pm 11$ years vs
$56 \pm 12$ years; $P=.002)$, and more of the unmatched hemodialysis patients were black ( $49 \%$ vs $22 \% ; P=.002)$ (Figure E2).

Missing values. In developing parsimonious and propensity models and identifying risk factors for death, 5-fold multiple imputation was used to impute missing values. ${ }^{18}$ The tables indicate the number of values missing for each variable. For example, of the 58 variables used for the propensity score, 21 had no missing data, 19 had $<5 \%$ missing data, 3 had $5 \%$ to $20 \%$ missing data, and 15 had $>20 \%$ missing data. The pattern of missing data appeared arbitrarily, so "missing at random" was assumed.

\section{Presentation}

Continuous variables are summarized as mean \pm standard deviation and as equivalent 15 th, 50th (median), and 85 th percentiles for skewed distributions; comparisons were made using the Wilcoxon rank-sum test. Categorical variables are summarized as frequencies and percentages, and comparisons were made using the $\chi^{2}$ test or Fisher's exact test when frequency was $<5$. Uncertainty is expressed by confidence limits equivalent to \pm 1 standard error $(68 \%)$.

\section{RESULTS}

\section{Characteristics of Hemodialysis and} Nonhemodialysis Patients: Surgical Patients

Compared with nonhemodialysis patients undergoing surgery for IE, hemodialysis patients were younger, and more were black and had a history of diabetes, carotid

TABLE 2. Characteristics of infective endocarditis before and after propensity matching

\begin{tabular}{|c|c|c|c|c|c|c|c|c|c|c|}
\hline \multirow[b]{2}{*}{ Characteristic } & \multicolumn{2}{|c|}{$\begin{array}{l}\text { Hemodialysis } \\
\quad(n=144)\end{array}$} & \multicolumn{2}{|c|}{$\begin{array}{l}\text { Nonhemodialysis } \\
\quad(n=1233)\end{array}$} & \multirow[b]{2}{*}{$P$ value } & \multicolumn{2}{|c|}{$\begin{array}{l}\text { Matched hemodialysis } \\
\qquad(\mathrm{n}=99)\end{array}$} & \multicolumn{2}{|c|}{$\begin{array}{l}\text { Matched nonhemodialysis } \\
\qquad(\mathrm{n}=99)\end{array}$} & \multirow[b]{2}{*}{$P$ value } \\
\hline & $\mathbf{n} *$ & No. $(\%)$ & $\mathbf{n} *$ & No. $(\%)$ & & $\mathbf{n}^{*}$ & No. $(\%)$ & $\mathbf{n}^{*}$ & No. $(\%)$ & \\
\hline \multicolumn{11}{|l|}{ Microbiology $\dagger$} \\
\hline Staphylococcus aureus & 144 & $61(42)$ & 1188 & $247(21)$ & $<.0001$ & 99 & $37(37)$ & 99 & $38(38)$ & $>.9$ \\
\hline $\begin{array}{l}\text { Coagulase-negative } \\
\text { staphylococcus }\end{array}$ & 144 & $38(26)$ & 1188 & $192(16)$ & .001 & 99 & $25(25)$ & 99 & $25(25)$ & .9 \\
\hline Enterococcus & 144 & $15(10)$ & 1188 & $121(10)$ & .9 & 99 & $13(13)$ & 99 & $13(13)$ & .9 \\
\hline Streptococcus viridans & 144 & $3(2.1)$ & 1188 & $202(17)$ & $<.0001$ & 99 & $3(3.0)$ & 99 & $5(5.1)$ & .4 \\
\hline Gram-positive cocci $i \ddagger$ & 122 & $1(0.81)$ & 858 & $54(6.3)$ & .02 & 81 & $0(0)$ & 85 & $7(8.2)$ & .007 \\
\hline Fungus & 144 & $4(2.7)$ & 1188 & $30(2.5)$ & .8 & 99 & $3(3.0)$ & 99 & $1(1.0)$ & .3 \\
\hline Polymicrobial & 144 & $3(2.1)$ & 1188 & $32(2.7)$ & .7 & 99 & $2(2.0)$ & 99 & $2(2.0)$ & $>.9$ \\
\hline Other & 144 & $7(4.9)$ & 1188 & $180(15)$ & .001 & 99 & $5(5.1)$ & 99 & $4(4.0)$ & .8 \\
\hline Not identified & 144 & $6(4.2)$ & 1188 & $92(7.7)$ & .12 & 99 & $5(5.1)$ & 99 & $4(4.0)$ & .7 \\
\hline \multicolumn{11}{|l|}{ Invasiveness $\oint$} \\
\hline Vegetations & 119 & $104(87)$ & 858 & $698(81)$ & .11 & 81 & $69(85)$ & 82 & $72(88)$ & 6 \\
\hline Cusp/leaflet abnormality & 119 & $84(71)$ & 858 & $394(46)$ & $<.0001$ & 81 & $52(64)$ & 82 & $54(66)$ & .8 \\
\hline Invasive disease & 119 & $56(47)$ & 873 & $406(47)$ & .9 & 81 & $38(47)$ & 82 & $32(39)$ & .3 \\
\hline Cellulitis $\|$ & 56 & $39(70)$ & 406 & $286(70)$ & $>.9$ & 38 & $27(71)$ & 32 & $22(69)$ & .4 \\
\hline Abscess $\|$ & 56 & $44(78)$ & 406 & $305(75)$ & .7 & 38 & $29(76)$ & 32 & $19(59)$ & .08 \\
\hline Abscess cavity $\|$ & 56 & $15(27)$ & 406 & $175(43)$ & .05 & 38 & $12(32)$ & 32 & $14(44)$ & .7 \\
\hline Pseudoaneurysm $\S$ & 56 & $1(1.7)$ & 406 & $42(10)$ & .05 & 38 & $1(2.6)$ & 32 & $1(3.1)$ & $>.9$ \\
\hline \multicolumn{11}{|l|}{ Valve involved } \\
\hline Aortic & 144 & $84(58)$ & 1233 & $825(67)$ & .04 & 99 & $55(55)$ & 99 & $52(52)$ & .8 \\
\hline Mitral & 144 & $90(62)$ & 1233 & $552(45)$ & $<.0001$ & 99 & $57(58)$ & 99 & $52(52)$ & 6 \\
\hline Tricuspid & 144 & $13(9.0)$ & 1233 & $125(10)$ & .7 & 99 & $12(12)$ & 99 & $9(9.0)$ & .5 \\
\hline Pulmonary & 144 & $0(0)$ & 1233 & $12(1.0)$ & 6 & 99 & $0(0)$ & 99 & $0(0)$ & - \\
\hline Any prosthetic valve & 144 & 28 (19) & 1233 & $439(36)$ & $<.0001$ & 99 & $23(23)$ & 99 & $23(23)$ & $>.9$ \\
\hline
\end{tabular}

*Patients with data available. †Final diagnosis. $\ddagger$ Not identified further. $\S$ Data available from January 1, 2002, onward. ||Percentage of invasive disease. 
TABLE 3. In-hospital outcomes before and after propensity matching

\begin{tabular}{|c|c|c|c|c|}
\hline & $\begin{array}{l}\text { Hemodialysis } \\
(\mathrm{n}=144)\end{array}$ & $\begin{array}{l}\text { Matched hemodialysis } \\
\qquad(\mathbf{n}=99)\end{array}$ & $\begin{array}{l}\text { Matched nonhemodialysis } \\
\qquad(\mathbf{n}=99)\end{array}$ & \\
\hline Outcome & $\begin{array}{c}\text { No. }(\%) \text { or } 15 \text { th } / 50 \text { th } / 85 \text { th } \\
\text { percentiles }\end{array}$ & $\begin{array}{c}\text { No. }(\%) \text { or } 15 \text { th } / 50 \text { th/ } / 85 \text { th } \\
\text { percentiles }\end{array}$ & $\begin{array}{c}\text { No. }(\%) \text { or } 15 \text { th } / 50 \text { th/85th } \\
\text { percentiles }\end{array}$ & $P$ value \\
\hline Hospital death & $18(13)$ & $13(13)$ & $5(5.1)$ & .05 \\
\hline Reoperation for bleeding or tamponade & $11(7.6)$ & $7(7.1)$ & $5(5.1)$ & 6 \\
\hline Stroke & $6(4.2)$ & $2(2.0)$ & $3(3.0)$ & 6 \\
\hline Perioperative myocardial infarction & $6(4.2)$ & $5(5.1)$ & $3(3.0)$ & .5 \\
\hline Respiratory failure & $36 / 86(42)$ & $26 / 60(43)$ & $17 / 57(30)$ & .13 \\
\hline Septicemia & $19(13)$ & $17(17)$ & $9(9.1)$ & .09 \\
\hline \multicolumn{5}{|l|}{ Length of stay } \\
\hline Intensive care unit, $\mathrm{h}$ & $49 / 120 / 529$ & $48 / 120 / 524$ & $28 / 96 / 284$ & .06 \\
\hline Postoperative, $\mathrm{d}$ & $8.1 / 15 / 32$ & $8 / 14 / 34$ & $7 / 12 / 26$ & .03 \\
\hline Hospital, d & $14 / 24 / 42$ & $14 / 24 / 42$ & $13 / 21 / 40$ & .13 \\
\hline
\end{tabular}

disease, and hypertension (Table 1). As a group, hemodialysis patients had lower hematocrit, greater left ventricular mass index, lower bilirubin concentration, and lower cholesterol levels at the time of surgery.

\section{Nature of the IE: Surgical Patients}

The most common causative organism in both hemodialysis and nonhemodialysis surgical patients was Staphylococcus aureus, but a higher percentage of hemodialysis patients had this organism compared with nonhemodialysis patients $(42 \%$ vs $21 \%$; Table 2). Left-sided IE was present in $96 \%$ of hemodialysis patients and $95 \%$ of nonhemodialysis patients, and right-sided IE in $9 \%$ of hemodialysis patients and $11 \%$ of nonhemodialysis patients. Prosthetic valve endocarditis (PVE) was present in $19 \%$ of hemodialysis patients, compared with $36 \%$ of nonhemodialysis patients. Invasive disease was present in $47 \%$ of both hemodialysis and nonhemodialysis patients. There was no invasive disease in right-sided IE in either group.

\section{Hospital Outcomes: Surgical Patients}

Among the hemodialysis patients, overall hospital mortality was $13 \% ; 4.2 \%$ had a stroke, $13 \%$ had septicemia, and $42 \%$ had respiratory failure (Table 3 ). In propensitymatched pairs, hospital mortality was higher $(13 \%$ vs $5.0 \%$ ) and intensive care unit and postoperative lengths of stay were longer in the hemodialysis patients compared with the nonhemodialysis patients, but other hospital outcomes were similar in the 2 groups.

Among hemodialysis patients with a catheter as dialysis access, the access was changed or the catheter replaced after surgery in $79 \%$ (46 of 58). Twelve patients had a preoperative pacemaker; it was removed in 6 patients, and epicardial leads were placed in 3 .

\section{Survival}

Survival at 1, 3, 5, 7, and 10 years in hemodialysis patients after surgery for IE was $60 \%, 38 \%, 25 \%, 16 \%$, and $8.4 \%$ (Figure 2, $A$ ). These figures are substantially lower than in the age-, race-, and sex-matched US population, approximately 15 percentage points below the $76 \%$, $54 \%$, and $40 \%$ survival at 1,3 , and 5 years for the general hemodialysis population, ${ }^{9}$ but higher than survival in hemodialysis patients with IE treated nonsurgically at our institution (outcomes reported in "Nonsurgically Treated Hemodialysis Patients"). Instantaneous risk of death was highest early after surgery and gradually decreased over the first 12 months (Figure E3, A). Thereafter, risk of death was constant at $22 \%$ /year $(68 \%$ confidence limits, $19 \%$ $25 \%$ /year).

Survival at $1,3,5,7$, and 10 years after surgery in matched patients was $56 \%$ versus $83 \%, 39 \%$ versus $70 \%, 24 \%$ versus $59 \%, 10 \%$ versus $49 \%$, and $1.4 \%$ versus $38 \%$ for hemodialysis versus nonhemodialysis patients, respectively (Figures 2, B, and E3, B). Cause of death was available for $52 \%$ (57 of 110) of matched patients; IE was listed as the cause in 10 hemodialysis patients and 5 nonhemodialysis patients.

Survival was similar for the 45 unmatched hemodialysis patients and the 99 matched hemodialysis patients $(P=.2$, log-rank test) (Figure E4).

\section{Risk Factors for Mortality: Surgical Patients on Hemodialysis}

Longer aortic clamp time was associated with higher early mortality after surgery in hemodialysis patients (Table 4). Risk factors for later mortality were left main disease, lower grade of aortic valve regurgitation, arteriovenous graft for vascular access, preoperative pacemaker, and IE caused by unidentified microorganisms (Table 4 and Figure 3).

\section{Reoperation: Surgical Patients}

Eleven of the hemodialysis patients underwent valve reoperation during follow-up. Reoperation at 1, 3, 5, and 7 years in hemodialysis patients was $8 \%, 15 \%, 18 \%$, 

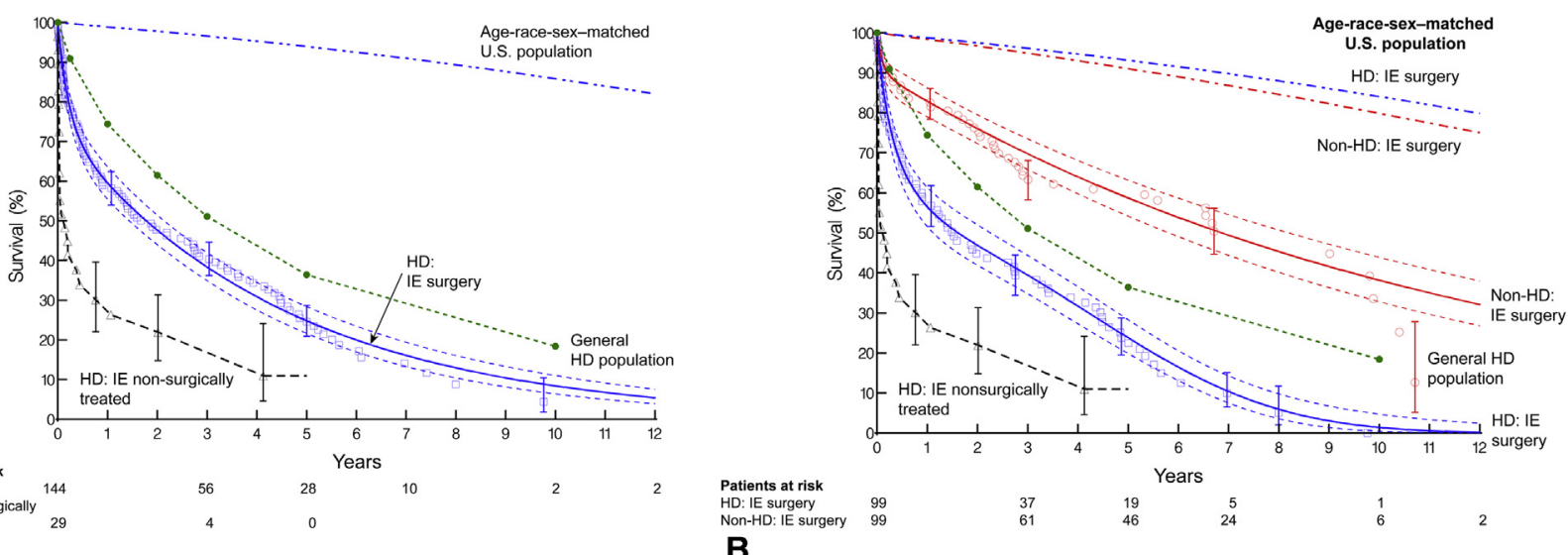

\section{B}

FIGURE 2. Survival after surgery for IE in hemodialysis patients referenced to (1) an age-, race-, and sex-matched US population (dash-dot-dot-dash line); (2) the general population of hemodialysis patients ${ }^{9}$ (dashed line with closed circles); and (3) nonsurgically treated endocarditis in hemodialysis patients (coarse dashed line and triangles). Each symbol represents a death positioned on the vertical axis by the Kaplan-Meier estimator. Vertical bars are confidence limits equivalent to \pm 1 standard error, and solid lines are parametric survival estimates enclosed within dashed $68 \%$ confidence bands equivalent to \pm 1 standard error. A, All hemodialysis patients. B, Propensity-matched patients. Deaths after surgery among matched non-HD patients are represented nonparametrically by open red circles and parametrically by a solid line enclosed within a dashed $68 \%$ confidence band; the red dash-dot-dash line is survival in an age-, race-, and sex-matched US population. $H D$, Hemodialysis; $I E$, infective endocarditis.

and $20 \%$ (Figure E5). After adjusting for competing risk of death, reoperation at these time points in hemodialysis patients was $3 \%, 7 \%, 13 \%$, and $13 \%$, respectively. Reoperation was similar for matched hemodialysis and nonhemodialysis patients at $1,3,5$, and 7 years: $4 \%$ versus $5 \%, 11 \%$ versus $9 \%, 17 \%$ versus $14 \%$, and $22 \%$ versus $18 \%$, respectively $(P>.9)$ (Figure E6). After adjusting for competing risk of death, reoperation at these time points was $2 \%, 5 \%, 12 \%$, and $12 \%$ for matched hemodialysis patients and $4 \%, 5 \%, 9 \%$, and $18 \%$ for matched nonhemodialysis patients, respectively (Figure E7).

TABLE 4. Incremental risk factors for death after valve surgery in hemodialysis patients

\begin{tabular}{lccc}
\hline \multicolumn{1}{c}{ Risk factor } & Coefficient \pm SE & $\begin{array}{c}\boldsymbol{P} \\
\text { value }\end{array}$ & $\begin{array}{c}\text { Reliability, } \\
\% *\end{array}$ \\
\hline $\begin{array}{l}\text { Early hazard phase } \\
\quad \text { Longer aortic clamp time } \dagger\end{array}$ & $0.83 \pm 0.22$ & .0001 & 53 \\
$\begin{array}{l}\text { Late hazard phase } \\
\quad \text { Left main disease }(\geq 50 \%\end{array}$ & $1.2 \pm 0.60$ & .04 & 73 \\
$\quad$ stenosis) & $0.94 \pm 0.38$ & .01 & 63 \\
$\quad \begin{array}{l}\text { Arteriovenous graft for } \\
\quad \text { dialysis access }\end{array}$ & $1.7 \pm 0.43$ & $<.0001$ & 68 \\
$\quad \begin{array}{l}\text { Pacemaker } \\
\text { Microorganism not } \\
\quad \text { identified }\end{array}$ & $2.3 \pm 0.52$ & $<.0001$ & 80 \\
$\quad \begin{array}{l}\text { Lower aortic valve } \\
\text { regurgitation grade }\end{array}$ & $-0.21 \pm 0.066$ & .001 & 72 \\
$\begin{array}{l}\text { SE, Standard error. *Percentage of times that the variable appeared in } 1000 \text { bootstrap } \\
\text { models. } \dagger(\text { Aortic occlusion time/60), scaled transformation. }\end{array}$ &
\end{tabular}

\section{Nonsurgically Treated Hemodialysis Patients}

Of the 29 hemodialysis patients with IE treated nonsurgically, 24 had a surgical indication but were not operated on; 22 were deemed inoperable by consultant cardiac surgeons because of high surgical risk and other comorbidities, 1 refused surgery, and surgery was postponed for 1 pending resolution of other infectious issues. Of these 29 patients, $16(55 \%)$ were male and $10(34 \%)$ were black; mean age was $62 \pm 9.7$ years.

Eighteen patients $(62 \%)$ had mitral valve involvement, 8 $(28 \%)$ had aortic valve involvement, $2(7.0 \%)$ had mitral and aortic valve involvement, and $1(3.4 \%)$ had mitral, aortic, and tricuspid valve involvement. Seven patients (24\%) had PVE. The causative agent was $S$ aureus in 17 patients $(59 \%)$, enterococcus in $6(21 \%)$, coagulase-negative staphylococcus in $3(10 \%)$, fungus in 1, Streptococcus viridans in 1 , and other in 1 .

Eleven patients (38\%) died in the hospital. Survival was $30 \%$ at 1 year, $22 \%$ at 3 years, and $11 \%$ at 5 years. All patients with PVE had died by the end of follow-up. Two survivors never had an indication for surgery. Twenty of the 24 patients with a defined surgical indication died during follow-up; their survival was $28 \%$ at 1 year, $19 \%$ at 3 years, and $9.4 \%$ at 5 years.

Of the 4 patients alive at end of follow-up, 2 had an indication for surgery based on vegetation size and mobility only, but did not have any hemodynamic indication and were apparently cured on follow-up. The other 2 patients had a hemodynamic indication for surgery; 1 was deemed inoperable because of high risk, and the other was compensated and asymptomatic with good heart function. 

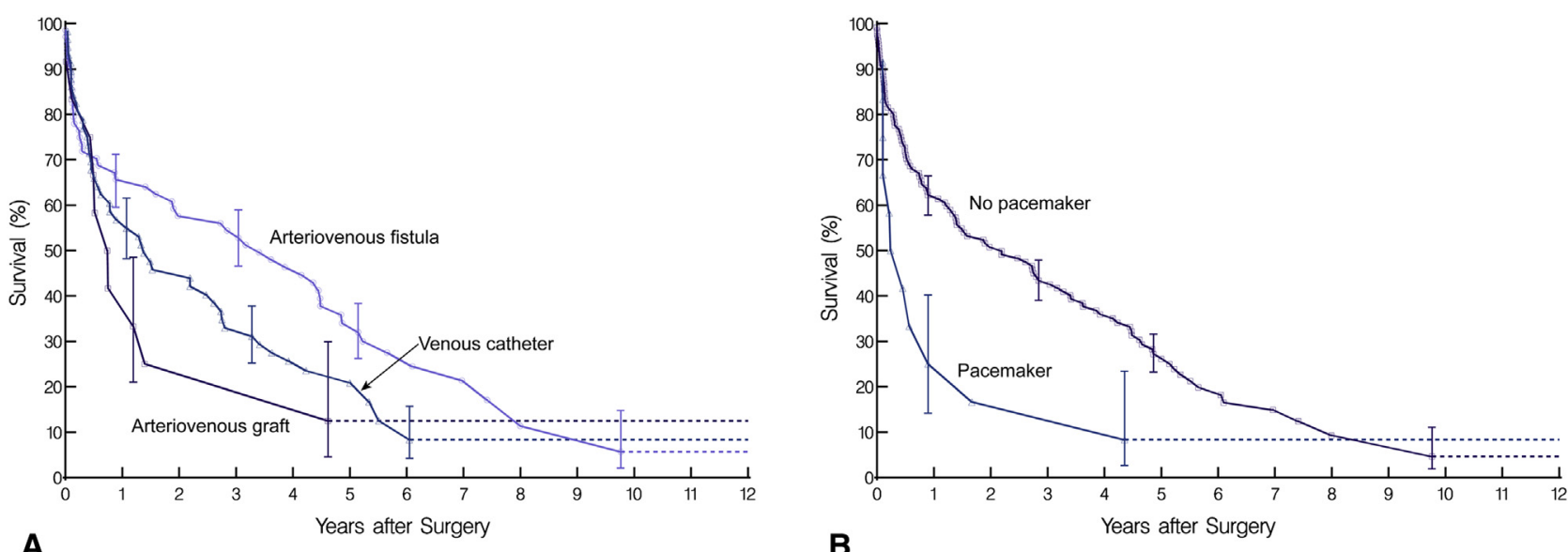

A

B

FIGURE 3. Survival after surgery for IE in hemodialysis patients, stratified by risk factors. Each symbol represents a death, and vertical bars represent confidence bands equivalent to \pm 1 standard error. A, Survival by dialysis access. B, Survival by the presence or absence of a preoperative pacemaker.

\section{DISCUSSION \\ Principal Findings}

This series represents a contemporary surgical experience with IE in hemodialysis patients at a surgically aggressive tertiary center operating on more than 100 patients with IE per year, and it shows that despite poor long-term survival, surgery for IE should be considered for patients on hemodialysis. This is because intermediate-term survival, although worse in hemodialysis patients with IE treated surgically than in similar nonhemodialysis patients, is only slightly worse than that expected in the general hemodialysis population and substantially better than in hemodialysis patients with nonsurgically treated IE.

\section{Findings in Context}

Black patients constitute more than $35 \%$ of those on dialysis in the US. ${ }^{17}$ In our study, $31 \%$ of surgically treated and $34 \%$ of nonsurgically treated chronic hemodialysis patients with IE were black. Although chronic kidney disease is more common in women than men, men are more likely to progress to end-stage renal disease. ${ }^{18}$ Consequently, our study included more men than women in the hemodialysis group.

In agreement with the present study, others have reported $S$ aureus as the leading cause of IE in hemodialysis patients, at approximately $50 \%{ }^{4,5,19,20}$ The presence of invasive and right-sided IE was similar in hemodialysis and nonhemodialysis patients, but native valve endocarditis was more common in the hemodialysis patients. This difference could be related to the increased exposure to pathogens from chronic hemodialysis access, leading to native valve endocarditis, as well as the small number of patients on dialysis who had undergone previous valve replacement.

Our hospital mortality after surgery compares favorably with the $24 \%$ mortality in dialysis patients reported in the
Society of Thoracic Surgeons database. ${ }^{3}$ Our institution's policy for managing patients with IE has shifted toward surgical intervention earlier in the course of disease, particularly in high-risk patients, such as those on hemodialysis. Early surgical intervention has been suggested by several other studies as well. ${ }^{19-23}$

The overall long-term survival of patients on hemodialysis is poor. ${ }^{9}$ In our study, survival after IE surgery was 15 percentage points lower in these patients, though still substantially better than the survival of hemodialysis patients with nonsurgically treated IE. Dohmen and colleagues ${ }^{7}$ reported $0 \%$ survival at approximately 5 years in dialysis patients undergoing surgery for IE.

Patients with renal failure are prone to earlier calcification of tissue-valve prostheses; however, in a study reported by Leither and colleagues, ${ }^{6}$ this did not translate into a survival advantage for mechanical valves. In dialysis patients without IE at our center, prosthetic valverelated complications are similar for both mechanical and bioprosthetic valves, which we attribute to the competing risk of mortality. ${ }^{24}$ Survival after surgery in hemodialysis patients depends on the timing of surgery, execution of an expeditious successful operation, and good postoperative management. Thus, in general, we prefer tissue valves for patients with IE to reduce the need for anticoagulation and thus simplify postoperative management and reduce the risk of hemorrhagic conversion of ischemic stroke and intracerebral bleeding. Mechanical valves are still considered for younger and healthier patients, however.

In this study, IE context (native or prosthetic) was not a risk factor for mortality, in agreement with our most recent study of patients with left-sided IE. ${ }^{10}$ Although other studies have reported worse outcomes with $S$ aureus $\mathrm{IE},{ }^{5,11}$ it was not associated with higher time-related mortality in the present study. The duration of cardiopulmonary 
bypass was a risk factor for worse early mortality. Longer cardiopulmonary bypass time is a surrogate for more advanced pathology, which requires more time for complete debridement. Mitral annulus calcification also adds to the difficulty, time, and risk of surgery. Dialysis patients with an arteriovenous fistula for vascular access are considered at lower risk for infection compared with patients with a catheter or arteriovenous graft.'

In this study, nearly one-half of the hemodialysis patients had arteriovenous fistulae for hemodialysis access, followed by catheters and arteriovenous grafts. The use of catheters for dialysis access has been associated with a greater risk of all-cause or infection-related mortality compared with arteriovenous grafts or fistulae ${ }^{25}$; surprisingly, in this study, the few arteriovenous grafts were associated with a greater risk of mortality compared with arteriovenous fistulae or catheter access. The association of a lower grade of aortic valve regurgitation with a higher risk of death is a surrogate for mitral valve IE, which continues to be associated with a poorer prognosis for our patients undergoing surgery for IE regardless of whether they are on hemodialysis. ${ }^{10}$

The prevalence of reoperation was similar for hemodialysis and nonhemodialysis patients, yet death from IE was more common in the hemodialysis patients. A possible explanation for this finding is that the hemodialysis patients were more often deemed inoperable when IE recurred.

Hemodialysis patients with nonsurgically treated IE represent a small but important subgroup of our study. Although these patients were either deemed inoperable or did not have a surgical indication and thus are not directly comparable to those undergoing surgery, they still provide a reference population in support of the value of surgical treatment for IE in hemodialysis patients.

\section{Study Strengths and Limitations}

Although this study is a single-center experience of 144 surgically treated IE patients on hemodialysis with follow-up data up to 12 years, it may be the largest series of its kind reported to date supporting surgical intervention in this high-risk population. It is an observational study, in which referral and selection bias may affect findings. For risk-adjusted comparison, we used propensity-score methods with 58 variables to identify matched pairs of hemodialysis and nonhemodialysis patients; however, important patient factors that might have affected outcomes but were not recorded or included in the propensity model may have biased our findings.

Hemodialysis patients who did not undergo surgery do not represent the natural history of IE, and many early deaths occurred among those not deemed surgical candidates. Duke criteria were incompletely documented in some of these patients. Moreover, because this is a single- center experience, our findings might not be generalizable. Time on hemodialysis is an important risk factor for mortality, ${ }^{9}$ but we were unable to extract this information from medical records.

\section{CONCLUSIONS}

Intermediate-term survival after surgery for IE in hemodialysis patients was substantially worse than that in non-hemodialysis patients, but only slightly worse than that in the general hemodialysis population and substantially better than that in hemodialysis patients with IE treated nonsurgically. We thus conclude that it remains worthwhile to operate for IE in patients on hemodialysis.

\section{Webcast}

You can watch a Webcast of this AATS meeting presentation by going to: http://webcast.aats.org/2016/Video/ Tuesday/05-17-16_Hall_E_1631_Raza-800.mp4.

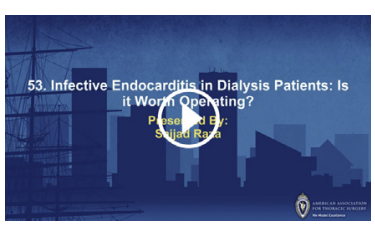

\section{Conflict of Interest Statement}

Authors have nothing to disclose with regard to commercial support.

\section{References}

1. Abbott KC, Agodoa LY. Hospitalizations for bacterial endocarditis after initiation of chronic dialysis in the United States. Nephron. 2002;91:203-9.

2. Saran R, Li Y, Robinson B, Ayanian J, Balkrishnan R, Bragg-Gresham J, et al. US Renal Data System 2014 Annual Data Report: epidemiology of kidney disease in the United States. Am J Kidney Dis. 2015;66(1 Suppl 1):Svii, S1-305.

3. Rankin JS, Milford-Beland S, O'Brien SM, Edwards FH, Peterson ED, Glower DD, et al. The risk of valve surgery for endocarditis in patients with dialysis-dependent renal failure. J Heart Valve Dis. 2007;16:617-22; discussion 622.

4. Spies C, Madison JR, Schatz IJ. Infective endocarditis in patients with end-stage renal disease: clinical presentation and outcome. Arch Intern Med. 2004;164: $71-5$.

5. Nori US, Manoharan A, Thornby JI, Yee J, Parasuraman R, Ramanathan V. Mortality risk factors in chronic haemodialysis patients with infective endocarditis. Nephrol Dial Transplant. 2006;21:2184-90.

6. Leither MD, Shroff GR, Ding S, Gilbertson DT, Herzog CA. Long-term survival of dialysis patients with bacterial endocarditis undergoing valvular replacement surgery in the United States. Circulation. 2013;128:344-51.

7. Dohmen PM, Binner C, Mende M, Bakhtiary F, Etz C, Pfannmüller B, et al. Outcome of aortic valve replacement for active infective endocarditis in patients on chronic hemodialysis. Ann Thorac Surg. 2015;99:532-8.

8. Arias E. United States life tables, 2008. Natl Vital Stat Rep. 2012;61:1-63.

9. United States Renal Data System. 2015 ADR reference tables. Available at: https://www.usrds.org/reference.aspx. Accessed March 29, 2017.

10. Hussain ST, Shrestha NK, Gordon SM, Houghtaling PL, Blackstone EH, Pettersson GB. Residual patient, anatomic, and surgical obstacles in treating active left-sided infective endocarditis. J Thorac Cardiovasc Surg. 2014;148: 981-8.e4. 
11. Manne MB, Shrestha NK, Lytle BW, Nowicki ER, Blackstone E, Gordon SM, et al. Outcomes after surgical treatment of native and prosthetic valve infective endocarditis. Ann Thorac Surg. 2012;93:489-93.

12. Kaplan EL, Meier P. Nonparametric estimation from incomplete observations. J Am Stat Assoc. 1958;53:457-81.

13. Blackstone EH, Naftel DC, Turner ME Jr. The decomposition of time-varying hazard into phases, each incorporating a separate stream of concomitant information. J Am Stat Assoc. 1986;81:615-24.

14. Andersen PK, Borgan O, Gill RD, Keiding N. Nonparametric estimation. In: Statistical Models Based on Counting Processes. New York: Springer-Verlag; 1993:176-331. 15. Breiman L. Bagging predictors. Mach Learn. 1996;24:123-40.

16. Rosenbaum PR, Rubin DB. The central role of the propensity score in observational studies for causal effects. Biometrika. 1983;70:41-55.

17. National Kidney Foundation. African Americans and kidney disease. Available at: https://www.kidney.org/news/newsroom/factsheets/African-Americans-andCKD. Accessed March 28, 2017

18. Hecking M, Bieber BA, Ethier J, Kautzky-Willer A, Sunder-Plassmann G, Säemann MD, et al. Sex-specific differences in hemodialysis prevalence and practices and the male-to-female mortality rate: the Dialysis Outcomes and Practice Patterns Study (DOPPS). PLoS Med. 2014;11:e1001750.

19. Nucifora G, Badano LP, Viale P, Gianfagna P, Allocca G, Montanaro D, et al. Infective endocarditis in chronic haemodialysis patients: an increasing clinical challenge. Eur Heart J. 2007;28:2307-12.

20. Kamalakannan D, Pai RM, Johnson LB, Gardin JM, Saravolatz LD. Epidemiology and clinical outcomes of infective endocarditis in hemodialysis patients. Ann Thorac Surg. 2007;83:2081-6.

21. Horstkotte D, Piper C. Chronic hemodialysis: high risk for manifestation of infective endocarditis with poor outcome. J Heart Valve Dis. 2005;14:8-10.

22. Salerno T, Ricci M. Invited commentary. Ann Thorac Surg. 2007;83:2086.

23. Kang DH, Kim YJ, Kim SH, Sun BJ, Kim DH, Yun SC, et al. Early surgery versus conventional treatment for infective endocarditis. N Engl J Med. 2012;366: 2466-73.

24. Kaplon RJ, Cosgrove DM III, Gillinov AM, Lytle BW, Blackstone EH, Smedira NG. Cardiac valve replacement in patients on dialysis: influence of prosthesis on survival. Ann Thorac Surg. 2000;70:438-41.

25. Wasse H. Catheter-related mortality among ESRD patients. Semin Dial. 2008;21: $547-9$.

Key Words: valve surgery, survival, reoperation

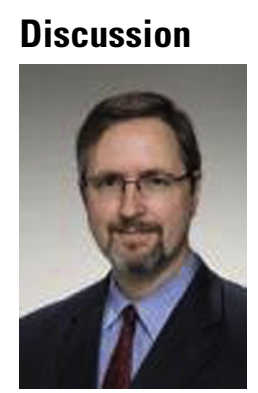

Dr F. Sellke (Providence, RI). I would like to congratulate the authors on their presentation regarding the outcomes of patients undergoing surgery for infective endocarditis in the dialysis population. Endocarditis is an increasing clinical problem worldwide and especially in the United States, where the use of intravenous narcotics is becoming near epidemic. The dialysis population is another group of patients with an increasing incidence who are prone to infective endocarditis due to their diminished immune system function and the repeated instrumentation of their vasculature.

In contrast to those patients abusing intravenous drugs, the dialysis population does not choose, in large part, to develop renal failure and to be dialyzed. Thus, it would be unethical to withhold surgical therapy in this group of patients regardless of the added benefit these patients may derive from surgery.

The study demonstrates that patients suffering from infective endocarditis and undergoing surgery have a poorer prognosis, but what is remarkable to me is that the general hemodialysis population has nearly as poor a prognosis. By the very nature of the study, the groups cannot be well controlled with regard to clinical variables. However, the authors have done a nice job attempting to make this a balanced, real-world comparison between the surgical results for endocarditis between dialysis and nondialysis patients.

I have several questions. First, we are seeing a large increase in the number of patients with infective endocarditis due to intravenous drug abuse. However, I did not see any mention of this in the paper. If one excludes these patients abusing drugs, do the results change? I would suspect that the outcomes in the nonhemodialysis population would actually improve versus the hemodialysis patient suffering from endocarditis.

Dr Raza. Thank you for your comments, Dr Sellke. We didn't specifically look into that, but it is well worth investigating. [These data were later abstracted. Five HD patients were active intravenous drug users. One of these patients was in the matched HD group. In the matched non-HD group, 4 patients were active intravenous drug users. Given these small numbers, we do not have enough data for any meaningful comparisons.]

Dr Sellke. Secondly, it is somewhat surprising that the incidence of prosthetic valve endocarditis was present in $19 \%$ of hemodialysis patients versus $36 \%$ of nonhemodialysis patients. Do you have an explanation for this and were the outcomes different between these 2 patient groups?

Dr Raza. There could be several reasons for this. First, hemodialysis patients are sicker than nonhemodialysis patients and have indwelling vascular access; thus, they are at higher risk in general of getting native valve endocarditis. Second, compared with nonhemodialysis patients, our guess is that fewer chronic hemodialysis patients have a history of cardiac surgery and an artificial valve in place.

Native or prosthetic valve endocarditis was not identified as a risk factor for mortality after surgery. This is in agreement with previous findings that in patients with endocarditis, long-term survival is similar whether we operate on a prosthetic valve or a native valve.

Dr Sellke. Interestingly, the duration of cardiopulmonary bypass was associated with a poorer short-term prognosis. Can you elaborate on why this may be the case? Is it due to just the inflammation due to bypass, the extent of structural deterioration and the need for debridement and reconstruction, or other factors?

Dr Raza. Longer cardiopulmonary bypass indicates a more challenging case with more aggressive disease, which requires more time for complete debridement.

Dr Sellke. Finally, there is no mention of the surgical treatment these patients received, whether it was debridement and prosthetic valve replacement, homograft replacement, or mainly, in the case of tricuspid and mitral valve endocarditis, valve repair. Chris Feindl, in the last issue of the Journal of Thoracic and Cardiovascular Surgery, said 
it was more important what you take out than what you put in which determined the recurrence of the endocarditis. What is your approach to this?

Dr Raza. Our approach is complete debridement of all infected tissue and foreign material, followed by generous irrigation. If we have to reconstruct the aortic root, the choice of material is an allograft. However, if for the aortic valve the annulus is preserved, then the choice of prosthesis is basically the same as for any other patient. We prefer tissue valves, because anticoagulation is an additional issue in these patients, and anticipated patient longevity is not that good.

For mitral valves, we prefer repair versus replacement. If replacement is done, it is done with chordal sparing.

Dr Sellke. Again, I would like to thank you for a very timely and interesting study.

Dr Raza. Thank you very much.

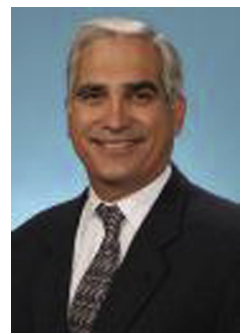

Dr R. Damiano (St. Louis, MO). Congratulations on a very nice study and very beautiful presentation. I was just going to elaborate a little bit on Dr Sellke's last question. I was very impressed with the dramatically poor survival in these patients, and I just wonder if you could elaborate if that has had an impact on your choice of valve prosthesis since most are dead in 5 years?

I also would like you to comment on the fact that generally it is in the hemodialysis patients that bioprosthetic valves have an incredibly short life expectancy because of the often profound and early calcification.
Dr Raza. Thank you, Dr Damiano. You are correct that dialysis patients have accelerated calcification of tissue valves. However, because of the poor life expectancy of patients on dialysis, bioprosthesis degeneration is uncommon. More important factors influencing survival are timing of surgery, whether you are able to complete debridement, and whether you have knowledge about the sensitivity of the bug. Those 3 factors are more important than choice of prosthesis.

We prefer tissue valves, and studies have shown similar survival with tissue versus mechanical valves in dialysis patients undergoing valve replacement surgery for indications other than infective endocarditis.

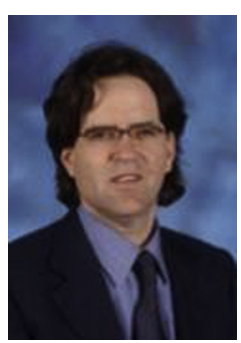

Dr N. Ad (Falls Church, Va). Did you also look into time to intervention, from diagnosis to intervention? Was there any delay in the dialysis patients because of their condition?

Dr Raza. No we did not; those data were not available.

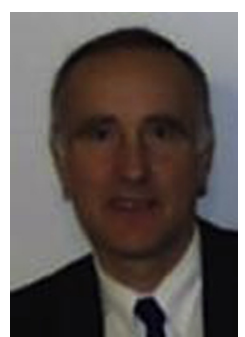

Dr G. Pettersson (Cleveland, Ohio). I just wanted to comment to the previous questions when it comes to difference in survival between mechanical and biological prostheses. In the noninfective endocarditis population, that did not make a difference in survival. 


\section{APPENDIX E1. SURGERY FOR INFECTIVE ENDOCARDITIS AMONG PERITONEAL DIALYSIS PATIENTS}

From January 1997 to January 2013,8 patients $(0.6 \%$ of 1413 patients undergoing surgery for infective endocarditis [IE]) were on chronic peritoneal dialysis. Median follow-up was 8 months, and follow-up was complete. Of these 8 patients, 1 died postoperatively in the hospital and 1 had septicemia. Survival at 1,3 , and 5 years was $38 \%, 38 \%$, and $19 \%$, respectively. One patient underwent reoperation at 2.1 years. These outcomes were similar to those for chronic hemodialysis patients.

APPENDIX E2. Variables used in the analyses

\begin{tabular}{|c|c|}
\hline \multirow{2}{*}{\multicolumn{2}{|c|}{ Preoperative }} \\
\hline & \\
\hline Demographics & Age $(\mathrm{y}),{ }^{*}$ sex,${ }^{*}$ race, ${ }^{*}$ weight $(\mathrm{kg})$, height $(\mathrm{cm})$, body surface area $\left(\mathrm{m}^{2}\right)$, body mass index $\left(\mathrm{kg} \cdot \mathrm{m}^{-2}\right)^{*}$ \\
\hline Symptoms & New York Heart Association functional class (I-IV), ${ }^{*}$ emergency operation, ${ }^{*}$ previous myocardial infarction $*$ \\
\hline Left ventricular dysfunction & Ejection fraction $(\%),{ }^{*}$ fractional shortening, relative wall thickness* \\
\hline Left ventricular structure & $\begin{array}{l}\text { End-diastolic diameter }(\mathrm{cm}), * \text { end-systolic diameter }(\mathrm{cm}),{ }^{*} \text { end-diastolic volume }(\mathrm{mL}) \text {, end-systolic volume }(\mathrm{mL}) \text {, } \\
\text { end-diastolic volume index }\left(\mathrm{mL} \cdot \mathrm{m}^{-2}\right) \text {, end-systolic volume index }\left(\mathrm{mL} \cdot \mathrm{m}^{-2}\right)\end{array}$ \\
\hline Left ventricular mass & Posterior wall thickness, intraventricular septal wall thickness, mass $(\mathrm{g})$, mass index $\left(\mathrm{g} \cdot \mathrm{m}^{-2}\right)^{*}$ \\
\hline Left atrial size & Diameter $(\mathrm{cm})$, volume $(\mathrm{mL})$, volume index $\left(\mathrm{mL} \cdot \mathrm{m}^{-2}\right), *$ \\
\hline Valve pathology & $\begin{array}{l}\text { Aortic valve: regurgitation,* stenosis*; mitral valve: regurgitation,* stenosis*; tricuspid valve: regurgitation,* } \\
\text { stenosis; pulmonary valve: regurgitation, }{ }^{*} \text { stenosis }\end{array}$ \\
\hline Valve etiology & $\begin{array}{l}\text { Aortic valve: rheumatic, degenerative; mitral valve: rheumatic, degenerative, ischemic, functional regurgitation, non- } \\
\text { structural dysfunction; tricuspid valve: normal, functional regurgitation* }\end{array}$ \\
\hline Coronary anatomy & $\begin{array}{l}\text { Left main trunk disease }(\geq 50 \% \text { stenosis }), * \text { left anterior descending disease }(\geq 50 \% \text { stenosis }), * \text { right coronary artery } \\
\text { disease }(\geq 50 \% \text { stenosis }),{ }^{*} \text { left circumflex disease }(\geq 50 \% \text { stenosis }) *\end{array}$ \\
\hline Other cardiac comorbidities & $\begin{array}{l}\text { Atrial fibrillation, }{ }^{*} \text { hypertension, }{ }^{*} \text { previous cardiac surgery, }{ }^{*} \text { complete heart block or pacer, }{ }^{*} \text { ventricular arrhythmia, }{ }^{*} \\
\text { prosthetic valve, }{ }^{*} \text { native valve (aortic, }{ }^{*} \text { mitral } * \text { ), previous aortic valve surgery, }{ }^{*} \text { mitral valve surgery, }{ }^{*} \text { tricuspid } \\
\text { valve surgery, }{ }^{*} \text { pulmonary valve surgery }\end{array}$ \\
\hline Noncardiac comorbidities & $\begin{array}{l}\text { Treated diabetes, }{ }^{*} \text { peripheral arterial disease, }{ }^{*} \text { history of smoking, }{ }^{*} \text { hypertension, }{ }^{*} \text { chronic obstructive pulmonary } \\
\text { disease, }{ }^{*} \text { previous stroke, }{ }^{*} \text { carotid disease, }{ }^{*} \text { bilirubin }\left(\mathrm{mg} \cdot \mathrm{dL}{ }^{-1}\right),{ }^{*} \text { hematocrit }(\%),{ }^{*} \text { cholesterol }\left(\mathrm{mg} \cdot \mathrm{dL}{ }^{-1}\right),{ }^{*} \\
\text { creatinine }\left(\mathrm{mg} \cdot \mathrm{dL}^{-1}\right), \text { blood urea nitrogen }\left(\mathrm{mg} \cdot \mathrm{dL}^{-1}\right), \text { creatinine clearance, glomerular filtration rate } \\
\left(\mathrm{mL} \cdot \mathrm{min}^{-1} \cdot 1.73 \mathrm{~m}^{-2}\right)\end{array}$ \\
\hline Microbiology & $\begin{array}{l}\text { Staphylococcus aureus, }{ }^{*} \text { coagulase-negative staphylococcus, }{ }^{*} \text { enterococcus, }{ }^{*} \text { Streptococcus viridans, gram-positive } \\
\text { cocci, fungal, polymicrobial, other, not identified }\end{array}$ \\
\hline Endocarditis invasiveness & $\begin{array}{l}\text { Vegetation, }{ }^{*} \text { cusp/leaflet abnormality, } * \text { invasive disease (mitral or aortic valve), cellulitis invasion (mitral or aortic } \\
\text { valve), cavity (mitral or aortic valve), }{ }^{*} \text { abscess (mitral or aortic valve), abscess cavity (mitral or aortic valve), } \\
\text { pseudoaneurysm (mitral or aortic valve), extent of invasive disease (mitral or aortic valve; anular circumference } \\
<1 / 3,1 / 3-1 / 2 \text {, full circumference)* }\end{array}$ \\
\hline Experience & Date of operation (years since 1/1/1997)* \\
\hline \multicolumn{2}{|l|}{ Procedural } \\
\hline Procedure & $\begin{array}{l}\text { Mitral valve repair/replacement, } * \text { aortic valve repair/replacement, }{ }^{*} \text { tricuspid valve repair/replacement, }{ }^{*} \text { pulmonary } \\
\text { valve repair/replacement, coronary artery bypass grafting, }{ }^{*} \text { any aortic root procedure, ascending aorta and arch } \\
\text { replacement, any congenital heart disease procedure, insertion of assist device, atrial septal defect/patent foramen } \\
\text { ovale closure }\end{array}$ \\
\hline
\end{tabular}

*Variables included in the propensity model. 

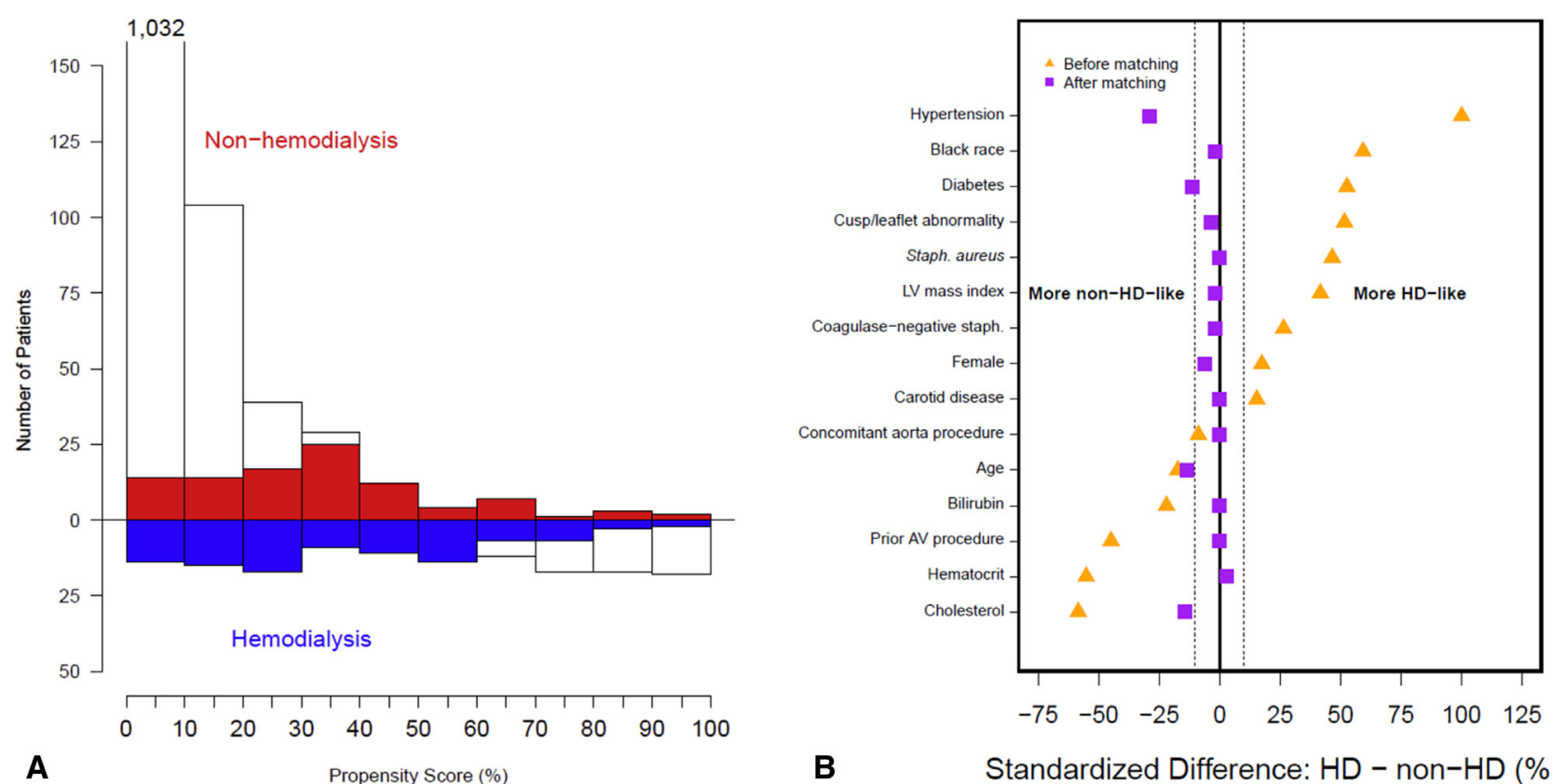

FIGURE E1. Propensity-score matching. A, Mirrored histogram of distribution of propensity scores for hemodialysis patients (bars below the 0 line) and nonhemodialysis patients (bars above the 0 line). Shaded areas represent matched patient pairs, showing that they cover the complete spectrum of cases. B, Covariable balance plot for selected variables. Standardized differences before and after matching between hemodialysis (HD) and nonhemodialysis (non$H D$ ) groups of patients undergoing surgery for IE are shown on the horizontal axis. staph., Staphylococcus; $L V$, left ventricular; $A V$, aortic valve.

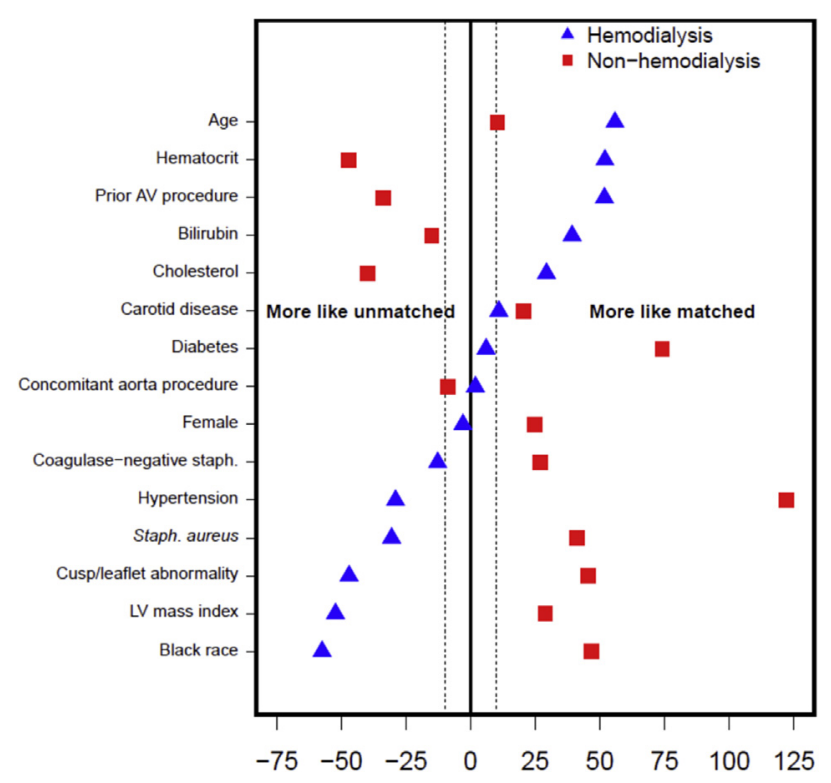

Standardized Difference: Matched - Unmatched (\%)

FIGURE E2. Covariable balance plot for selected variables. Standardized differences between matched and unmatched patients in the hemodialysis and nonhemodialysis groups undergoing surgery for IE are shown on the horizontal axis. $A V$, Aortic valve; staph., staphylococcus; $L V$, left ventricular. 

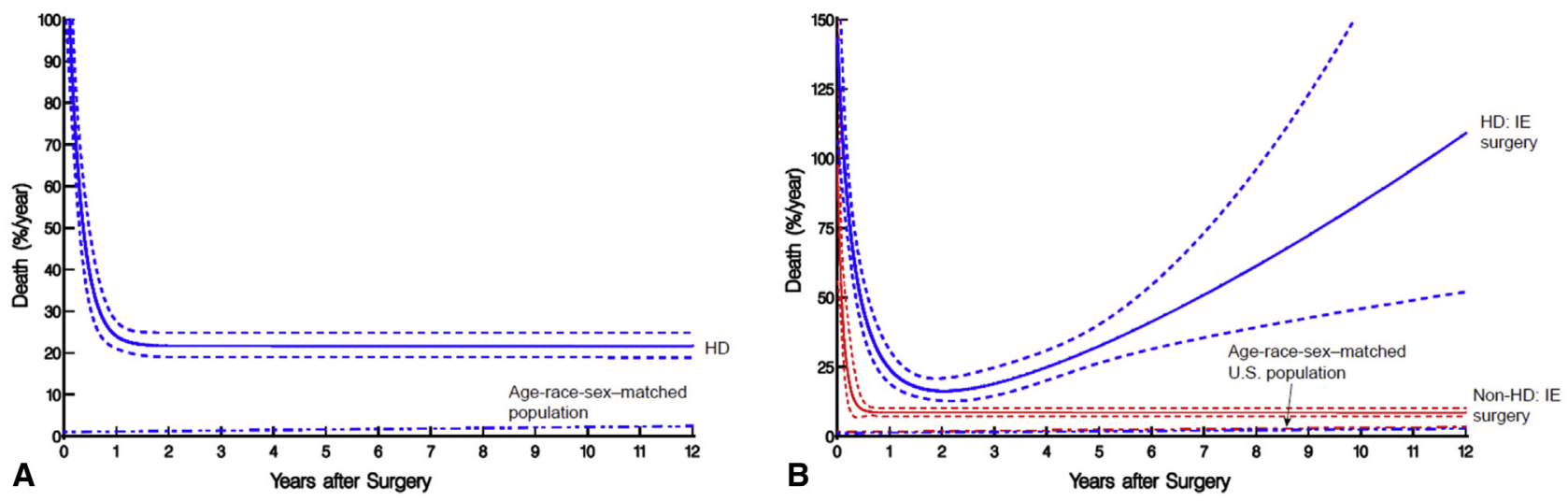

FIGURE E3. Unadjusted instantaneous risk of death (hazard function) after surgery for IE, referenced to an age-, race-, and sex-matched US population (dash-dot-dot-dash lines). Solid lines are parametric hazard estimates enclosed within dashed $68 \%$ confidence bands equivalent to \pm 1 standard error. A, All hemodialysis $(H D)$ patients. B, Propensity-matched HD and nonhemodialysis (non-HD) patients, with survival in the US population matched for age, race, and sex of non-HD patients shown by the red dash-dot-dash line and for HD patients by the blue dash-dot-dot-dash line. IE, Infective endocarditis.

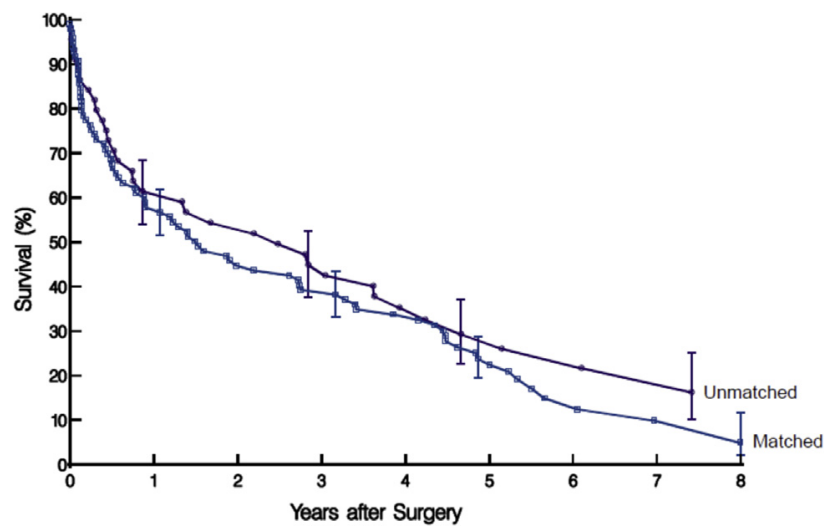

FIGURE E4. Long-term survival after surgery for IE in matched versus unmatched hemodialysis patients (matched, $\mathrm{n}=99$; unmatched, $\mathrm{n}=45$ ). 


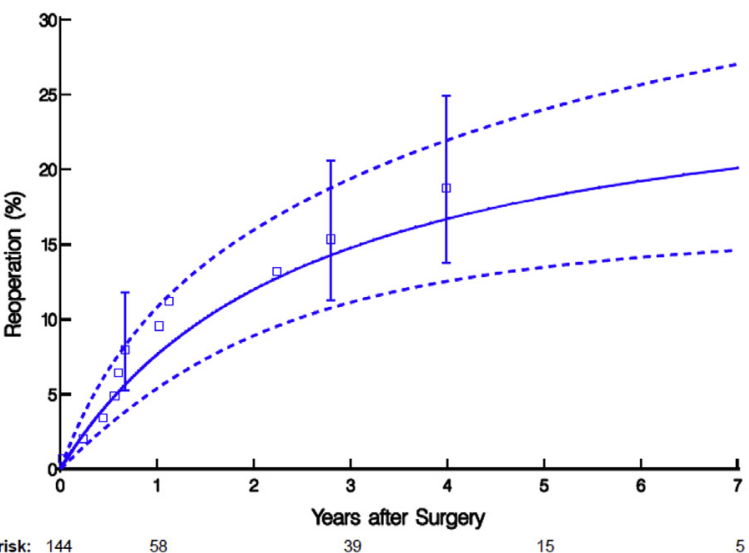

Patien

FIG enclosed within a dashed $68 \%$ confidence band equivalent to \pm 1 standard error. Each symbol represents a reoperation positioned on the vertical axis by the Kaplan-Meier estimator; vertical bars are confidence limits equivalent to \pm 1 standard error. B, Instantaneous risk of reoperation (hazard function). Solid line is parametric hazard estimate enclosed within a dashed $68 \%$ confidence band equivalent to \pm 1 standard error.

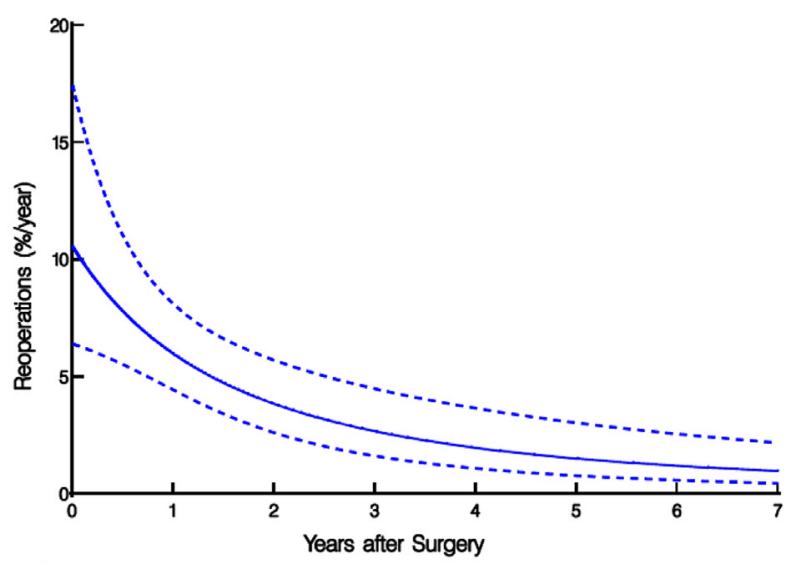

B

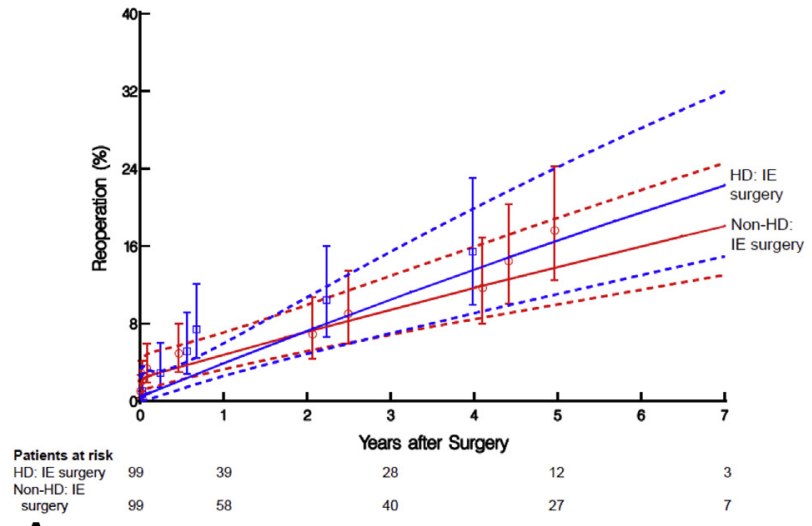

A

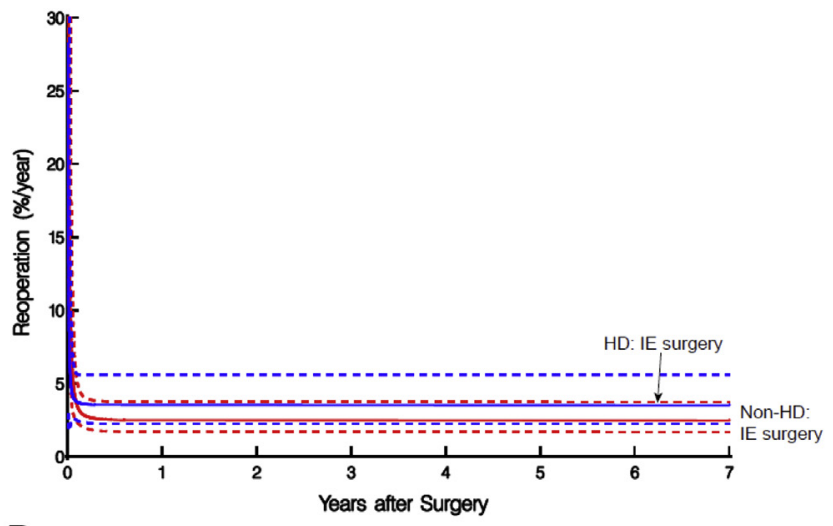

B 

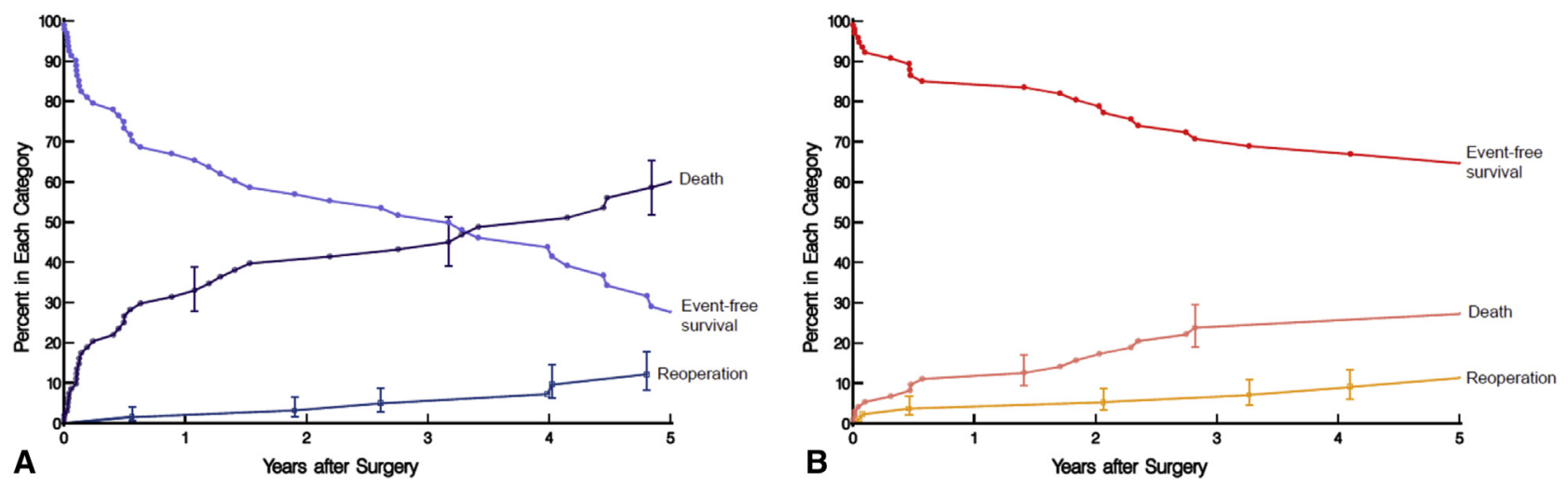

FIGURE E7. Competing risks of death and reoperation after surgery for IE. Each symbol represents an event or patients removed from event-free survival; vertical bars are confidence limits equivalent to \pm 1 standard error. A, Matched patients on hemodialysis. B, Matched patients not on hemodialysis.

TABLE E1. Surgical details

\begin{tabular}{|c|c|c|c|c|c|c|c|c|c|c|}
\hline \multirow[b]{2}{*}{ Characteristic } & \multicolumn{2}{|c|}{$\begin{array}{c}\text { Hemodialysis } \\
(n=144) \\
\end{array}$} & \multicolumn{2}{|c|}{$\begin{array}{l}\text { Nonhemodialysis } \\
\quad(\mathbf{n}=\mathbf{1 2 3 3})\end{array}$} & \multirow[b]{2}{*}{$P$ value } & \multicolumn{2}{|c|}{$\begin{array}{c}\text { Matched } \\
\text { hemodialysis }(n=99)\end{array}$} & \multicolumn{2}{|c|}{$\begin{array}{l}\text { Matched nonhemodialysis } \\
\qquad(\mathrm{n}=99)\end{array}$} & \multirow[b]{2}{*}{$P$ value } \\
\hline & $\mathbf{n}^{*}$ & No. $(\%)$ & n* & No. $(\%)$ & & $\mathbf{n}^{*}$ & No. $(\%)$ & $\mathbf{n}^{*}$ & No. $(\%)$ & \\
\hline \multicolumn{11}{|l|}{ Aortic valve } \\
\hline Repair & 144 & $6(4.2)$ & 1233 & $45(3.6)$ & .8 & 99 & $4(4.0)$ & 99 & $4(4.0)$ & $>.9$ \\
\hline Replacement & 144 & $81(56)$ & 1233 & $805(65)$ & .03 & 99 & $52(53)$ & 99 & $54(55)$ & .8 \\
\hline Allograft & 81 & $38(47)$ & 805 & $525(65)$ & .0002 & 52 & $24(46)$ & 54 & $24(44)$ & .9 \\
\hline Bioprosthesis & 81 & $38(47)$ & 805 & $232(29)$ & .0001 & 52 & $25(48)$ & 54 & $25(46)$ & .8 \\
\hline Mechanical prosthesis & 81 & $5(6.2)$ & 805 & $45(5.6)$ & .8 & 52 & $3(5.8)$ & 54 & $5(9.3)$ & .5 \\
\hline Autograft & 81 & $0(0)$ & 805 & $3(0.37)$ & $<.9$ & 52 & $0(0)$ & 54 & $0(0)$ & - \\
\hline \multicolumn{11}{|l|}{ Mitral valve } \\
\hline Repair & 144 & $40(28)$ & 1233 & $298(24)$ & .3 & 99 & $27(27)$ & 99 & $21(21)$ & .3 \\
\hline Replacement & 144 & $55(38)$ & 1233 & $336(27)$ & .006 & 99 & $36(36)$ & 99 & $40(40)$ & .6 \\
\hline Bioprosthesis & 55 & $40(73)$ & 336 & $274(82)$ & .13 & 36 & $24(67)$ & 40 & $33(82)$ & .16 \\
\hline Mechanical prosthesis & 55 & $15(27)$ & 336 & $62(18)$ & .13 & 36 & $12(33)$ & 40 & $7(18)$ & .2 \\
\hline \multicolumn{11}{|l|}{ Tricuspid valve } \\
\hline Repair & 144 & $28(19)$ & 1233 & $193(16)$ & .2 & 99 & $19(19)$ & 99 & $23(23)$ & .5 \\
\hline Replacement & 144 & $6(4.2)$ & 1233 & $34(2.8)$ & .3 & 99 & $6(6.1)$ & 99 & $2(2.0)$ & .15 \\
\hline \multicolumn{11}{|l|}{ Pulmonary valve } \\
\hline Repair & 144 & $0(0)$ & 1233 & $5(0.4)$ & $>.9$ & 99 & $0(0)$ & 99 & $1(1.0)$ & .3 \\
\hline Replacement & 144 & $0(0)$ & 1233 & $11(0.9)$ & .6 & 99 & $0(0)$ & 99 & $1(1.0)$ & .3 \\
\hline
\end{tabular}

*Patients with data available. 
TABLE E2. Patient factors associated with hemodialysis versus nonhemodialysis

\begin{tabular}{|c|c|c|c|}
\hline Factor & Coefficient \pm SE & $P$ value & Reliability, $\% *$ \\
\hline \multicolumn{4}{|l|}{ Higher likelihood of hemodialysis } \\
\hline Black race & $1.2 \pm 0.27$ & $<.0001$ & 97 \\
\hline History of diabetes & $0.67 \pm 0.23$ & .004 & 87 \\
\hline Hypertension & $3.5 \pm 0.54$ & $<.0001$ & 99 \\
\hline Staphylococcus aureus & $1.4 \pm 0.27$ & $<.0001$ & 99 \\
\hline Coagulase-negative staphylococcus & $1.2 \pm 0.30$ & $<.0001$ & 99 \\
\hline Abnormality of cusp/leaflet & $0.86 \pm 0.27$ & .002 & 85 \\
\hline Carotid disease & $0.70 \pm 0.27$ & .01 & 56 \\
\hline Lower hematocrit $\dagger$ & $1.6 \pm 0.58$ & .005 & 86 \\
\hline Higher left ventricular mass index $\ddagger$ & $1.5 \pm 0.38$ & .0002 & 58 \\
\hline Concomitant aorta procedure & $0.64 \pm 0.29$ & .03 & 82 \\
\hline \multicolumn{4}{|l|}{ Higher likelihood of nonhemodialysis } \\
\hline Older age $\S$ & $0.53 \pm 0.16$ & .0006 & 97 \\
\hline Higher bilirubin $\|$ & $0.55 \pm 0.16$ & .0007 & 72 \\
\hline Higher cholesterol $\uparrow$ & $1.6 \pm 0.36$ & $<.0001$ & 84 \\
\hline Previous aortic valve procedure & $1.3 \pm 0.34$ & .0002 & 78 \\
\hline
\end{tabular}

$S E$, Standard error. *Percentage of times that the variable appeared in 1000 bootstrap models. $\dagger(40 /$ hematocrit), inverse transformation. $\ddagger$ Log(left ventricular mass index), logarithmic transformation. §Exp(age/50), exponential transformation. $\| \log ($ bilirubin), logarithmic transformation. $\uparrow \log ($ cholesterol), logarithmic transformation. 